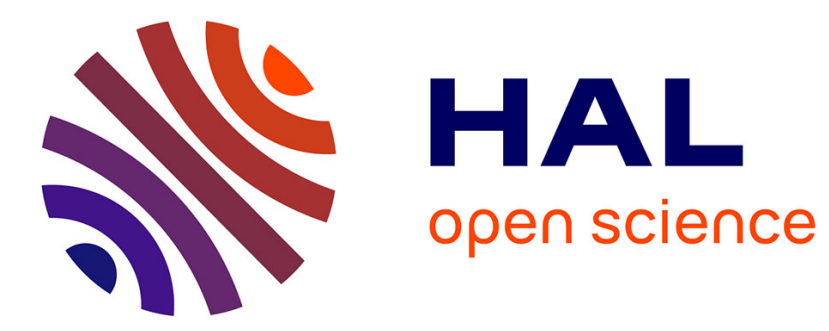

\title{
Multiple-Edge EXAFS Study of Solid and Liquid CuBr
} M. Minicucci, A. Di Cicco

\section{To cite this version:}

M. Minicucci, A. Di Cicco. Multiple-Edge EXAFS Study of Solid and Liquid CuBr. Journal de Physique IV Proceedings, 1997, 7 (C2), pp.C2-1027-C2-1028. 10.1051/jp4:19972128 . jpa-00255188

\section{HAL Id: jpa-00255188 https://hal.science/jpa-00255188}

Submitted on 1 Jan 1997

HAL is a multi-disciplinary open access archive for the deposit and dissemination of scientific research documents, whether they are published or not. The documents may come from teaching and research institutions in France or abroad, or from public or private research centers.
L'archive ouverte pluridisciplinaire HAL, est destinée au dépôt et à la diffusion de documents scientifiques de niveau recherche, publiés ou non, émanant des établissements d'enseignement et de recherche français ou étrangers, des laboratoires publics ou privés. 


\title{
Multiple-Edge EXAFS Study of Solid and Liquid $\mathrm{CuBr}$
}

\author{
M. Minicucci and A. Di Cicco
}

\author{
UdR INFM, Dipartimento di Matematica e Fisica, Università di Camerino, Via Madonna delle Carceri, \\ 62032 Camerino (MC), Italy
}

\begin{abstract}
X-ray absorption measurements of solid and liquid $C u B r$ have been carried out around the $C u$ and $B r$ $\mathrm{K}$-edge at $295,400,600,670,793 \mathrm{~K}$. EXAFS data of both edges have been analyzed simultaneously, for the first time on a binary compound, by using the $a b$-initio multiple-scattering GNXAS method. Multiple-edge EXAFS refinement allowed us to obtain an accurate determination of the first-neighbor distribution as a function of temperature. Mean bond distance, variance and skewness of the distribution have been measured and their statistical errors evaluated. A slight contraction of the most probable $\mathrm{Cu}-\mathrm{Br}$ bond-length is observed at high temperatures approaching the superionic and the liquid phases ( $T \geq 670 \mathrm{~K}$ ). The asymmetry of the first-neighbor distribution is found to increase at high-temperature. Evidence for nearly-covalent bonding is found in liquid $\mathrm{CuBr}$.
\end{abstract}

\section{INTRODUCTION}

Copper halides are an interesting class of materials showing peculiar electronic and structural properties. In particular, superionic conductivity occurs in $\mathrm{CuBr}$ and $\mathrm{CuCl}$ before melting. Several solid-phase transitions take place increasing temperature. A high mobility of copper is observed in the high-temperature phases. Several EXAFS (Extended $\mathrm{X}$-Ray Absorption Spectroscopy) $[1,2,3]$ studies were carried out in solid $\mathrm{CuBr}$. Neutron Diffraction works were also performed on solid [4] and liquid [5] $C u B r$. Important anharmonic contributions in solid $C u B r$ were found using both spectroscopies, even at low temperatures. In liquid $C u B r, C u-B r$ and $B r-B r$ distributions were found essentially of "ionic" character, while the Cu-Cu distribution was found to be featureless. [5] In this brief report, we present the results of an accurate EXAFS study of solid and liquid $C u B r$ at various temperatures. EXAFS measurements around the $\mathrm{Cu}$ and $\mathrm{Br} \mathrm{K}$-edge were performed in transmission mode at LURE (Orsay, France), on beamlines D42 and D44. Raw data are analyzed by using the ab-initio multiple-scattering GNXAS method. [6,7] $\mathrm{Cu}$ and $\mathrm{Br} \mathrm{K}$-edge are studied simultaneously, using a recently developed multiple-edge data-analysis [8] approach which allows an accurate and reliable determination of the short-range partial distribution functions.

\section{RESULTS AND DISCUSSION}

\subsection{Solid $\mathrm{CuBr}$}

The model (solid line) and experimental (dots) $C u$ and $B r$ K-edge EXAFS spectra at room temperature (RT) are compared in Fig. 1. The overall agreement is excellent. The calculated signal (Total) takes into account all of the two-atom and three-atom configurations up to the third shell around the $B r$ and $C u$ photoabsorbing sites. The individual multiple-scattering $\gamma^{(2)}, \gamma^{(3)}$ or $\eta^{(3)}$ signals [6] are also shown in Fig. 1. The small discrepancies between the experimental and calculated data are due to higher-order or farther shell contributions. However, the dominant contribution is due to the first-shell atoms in both spectra.

The first-neighbour bond length probability density $p(r)$ was modelled using a Euler's $\Gamma$-like distribution: [9]

$$
p(r)=\frac{2}{\sigma|\beta| \Gamma\left(4 / \beta^{2}\right)}\left(\frac{4}{\beta^{2}}+\frac{2(r-R)}{\sigma \beta}\right)^{\frac{4}{\beta^{2}}-1} \exp \left[-\left(\frac{4}{\beta^{2}}+\frac{2(r-R)}{\sigma \beta}\right)\right] .
$$

This expression depends on three parameters: the average distance $R$, the variance $\sigma^{2}$ and the adimensional skewness parameters $\beta=K_{3} / \sigma^{3}$, where $K_{3}$ is the third cumulant of the distribution.

Best-fit results for the average distance, variance, and third cumulant $K_{3}$ of the first-shell distribution are reported in Table $I$ as a function of temperature (statistical errors in brackets). The average distance presents a regular trend as a function of temperature in the $\gamma$ phase, while a slight contraction is observed in the high-temperature $\beta$ phase. The bond variance and skewness parameter also increase as a function of temperature. The bond variance value at 295 $\mathrm{K}$ is in good agreement with the shell-model calculation presented in ref. [2]. However, a stronger disorder is found at higher temperatures, as revealed by both variance and third cumulant values. The trend of the third cumulant of the distribution, calculated from the corresponding values of the $\beta$ skewness parameter, is very interesting. The value 
at $295 \mathrm{~K}$ is in a good agreement with previous resuits [2], while $K_{3}$ rapidly increases at high temperature leading to strongly asymmetric first-neighbour distributions. In Fig. 2 the two-body distribution functions at $T=295 K$, $T=600 K$ and $T=793 K$, reconstructed from EXAFS data, are reported. The error bars in Fig. 2 have been estimated from the $2 \sigma$ statistical errors on the individual parameters and should be considered as maximum uncertainty on the shape of the distribution. The distribution is asymmetric even at room temperature. Asymmetry and width of the distribution increase as a function of temperature up to the the liquid phase. The most interesting feature is that while the average $\mathrm{Cu}-\mathrm{Br}$ distance is nearly constant; both the foot and the most-probable value of the distribution move of about $0.06 \AA$ to shorter distances. This effect is related to the asymmetry of the distribution, which results to be steeper at short distances but is still different from zero in an intermediate range of distances.

Table 1: Best-fitting parameters of crystalline $\mathrm{CuBr}$.

\begin{tabular}{lllll} 
& $\mathrm{T}(\mathrm{K})$ & $R(\AA)$ & $\sigma^{2}\left(10^{-2} \AA^{2}\right)$ & $K_{3}\left(10^{-3} \AA^{3}\right)$ \\
\hline$\gamma-C u B r$ & 295 & $2.453(2)$ & $1.00(5)$ & $0.36(5)$ \\
& 400 & $2.460(4)$ & $1.7(1)$ & $1.3(2)$ \\
$\beta-C u B r$ & 600 & $2.466(7)$ & $2.5(2)$ & $3.0(5)$ \\
\hline
\end{tabular}

\subsection{Liquid $\mathrm{CuBr}$}

In liquid $C u B r$, we performed a short-range refinement of the two-body distribution function $g_{C u B r}(r)$ using a model $g(r)$ decomposed into one peak plus the long-range tail. Other systems were investigated using this method, obtaining excellent results. $[8,9]$ The reconstructed two-body $g_{C u B r}(r)$ at $793 \mathrm{~K}$ is shown in Fig. 2 and compared with those of the solid phase. The shape of the first-peak is substantially similar to that of the high-temperature solid phase. In the liquid, a flat non-zero distribution is found at longer distances. The first-neighbor peak is found to be much narrower than indicated by a previous neutron diffraction study. However, it is demonstrated that the present shape of the peak is consistent with the original neutron diffraction $S(Q)$ data. [10] Present findings indicate evidence of nearly-covalent bonding in the liquid phase, showing that previous measurements have to be reconsidered in light of the new results. Further details on liquid $C u B r$ are reported elsewhere. [10]

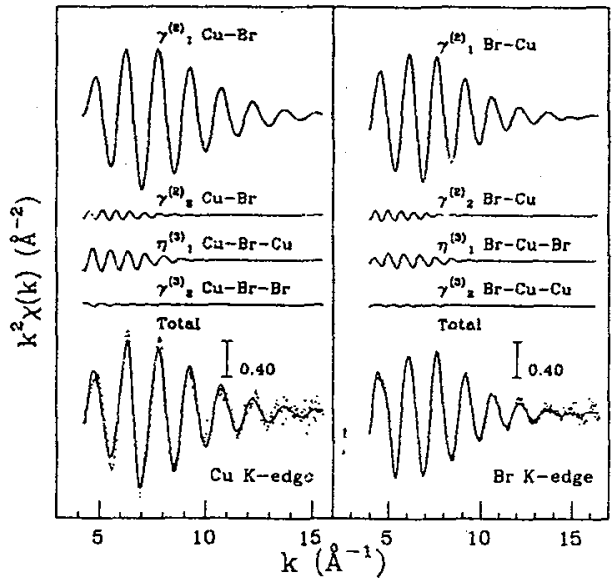

Figure 1: Experimental and calculated EXAFS spectra of $\mathrm{CuBr}$ at room temperature.

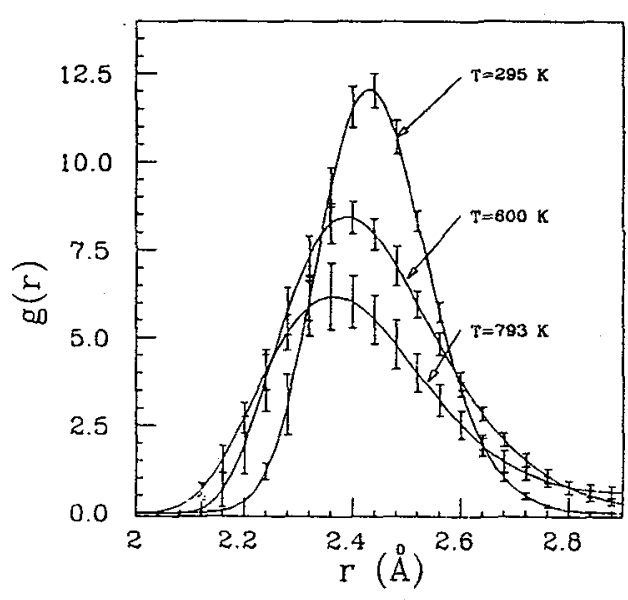

Figure 2: Two-body $g_{C u B r}(r)$ distribution functions at the temperatures of 295,600 , and $793 \mathrm{~K}$.

\section{References}

(1) J. B. Boyce, T. M. Hayes, and J. C. Mikkelsen, Jr., Phys. Rev. B 23 (1981) 2876.

[2] J. M. Tranquada and R. Ingalls, Phys. Rev. B 28 (1983) 3520.

[3] M. Inui and S. Takeda, Jpn. J. Appl. Phys. 32 (1993) Suppl. 32-2, 697-699.

[4] F. Altorfer, B. Graneli, P. Fischer and W. Bührer, J. Phys.: Cond. Matter 6 (1994) 9949.

[5] D. A. Allen and R. A. Howe, J. Phys.: Condens. Matter 4 (1992) 6029-6038.

[6] A. Filipponi, A. Di Cicco, and C. R. Natoli, Phys. Rev. B 52 (1995) 15122.

[7] A. Filipponi and A. Di Cicco, Phys. Rev. B 52 (1995) 15135.

[8] A. Di Cicco, Phys. Rev. B 53 (1996) 6174.

[9] A. Filipponi and A. Di Cicco, Phys. Rev. B 51 (1995) 12322.

[10] A. Di Cicco, M. Minicucci, A. Filipponi, (submitted). 